\title{
Взаимосвязи технологических процессов глубокой переработки птичьего помета
}

Запевалов М.В., доктор технических наук, профессор кафедры «Эксплуатация машинно-тракторного парка, и технология и механизация животноводства»

Качурин В.В., кандидат технических наук, доцент кафедры «Технический сервис машин, оборудования и безопасности жизнедеятельности»

Южно-Уральский государственный аграрный университет, г. Челябинск

Наруков Е.н., первый заместитель генерального директора

ПАО «Птицефабрика Челябинская»

\begin{abstract}
Аннотащия: Разработана схема комплексного технологического процесса глубокой переработки птичьего помета, состоящая из отдельных технологических процессов: предварительного подогрева помета, высокотемпературной суики, брикетирования, газификации методом пиролиза и приготовления органо-минерального удобрения. На основе данной схемы разработана блок-схема бнешних сбязей процесса глубокой переработки помета, которые предстаблены как система с детализацией по основным технологическим процессам. При разработке очередного этапа переработки помета учитыбается его состояние на предыдущем этапе, то есть произбодится решение многоэтапной задачи, причем на каждом этапе предусматривается выполнение определенного количества технологических операций для достижения желаемого результата. При этом отдельнье операции не рассматрибаются Вследствие их достаточной изученности и неизменности. Определены основные факторы и разработана операторная схема технологии глубокой переработки помета.
\end{abstract}

Ключебые слова: птичий помет, переработка, технологические процессы, связи, бысокотемпературная сушка, пиролиз, органо-минеральное удобрение.

Введение. Применение современных технологий клеточного содержания птицы позволило увеличить ее поголовье и полностью обеспечить внутренний рынок конкурентоспособными продуктами - яйцом и мясом. Однако вместе с увеличением производства основной продукции увеличился и выход отходов производства, в первую очередь, птичьего помета. При клеточном содержании птицы помет является благоприятной средой обитания различных патогенных микроорганизмов: бактерий, стафилококков, сальмонелл, следовательно, при большом скоплении он опасен для окружающей среды. В последние годы предпринимаются меры по ужесточению ответственности за загрязнение окружающей среды, повышению эффективности утилизации отхо- дов производства и коммунального хозяйства, совершенствованию контроля экологических вопросов [1]. При удалении помета из птичника необходима его переработка, безопасная для окружающей среды. Птичий помет в большей степени является органическим веществом, которое содержит достаточно высокое количество полезных макро- и микроэлементов. Он является хорошим компонентом для приготовления комплексного органо-минерального удобрения [2-4]. Эффективность этого удобрения зависит от технологии переработки помета, которая должна быть интегрирована в единый замкнутый технологический процесс птицеводческого предприятия [5].

Цель исследования - повышение эффективности глубокой переработки птичьего помета.
Материал и методика исследований. В результате теоретических и экспериментальных исследований по утилизации помета разработана схема комплексного технологического процесса его глубокой переработки. Комплексный процесс состоит из основных технологических процессов: предварительного подогрева помета, высокотемпературной сушки, брикетирования, газификации и приготовления органо-минерального удобрения, которые взаимосвязаны между собой по функциональным, материальным, энергетическим и технологическим аспектам. В том случае, когда газификация высушенного помета производится только для получения горючего газа, необходимого для его сушки, остальной высушенный помет целесообразно ис- 


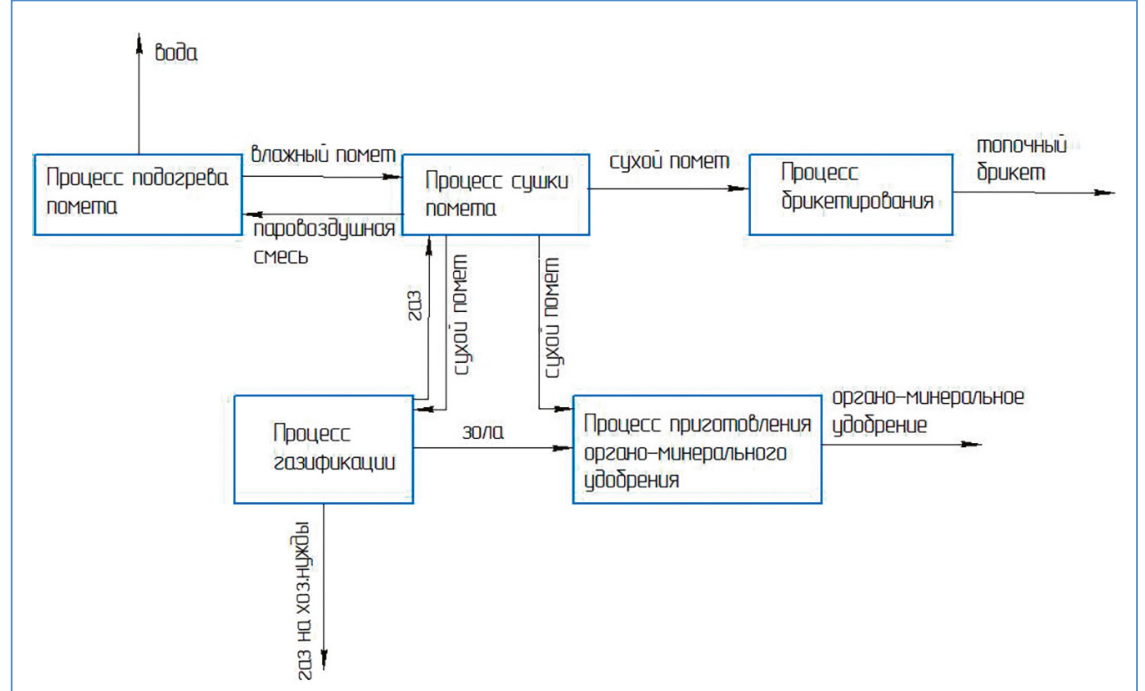

Рисунок 1. Схема комплексного технологического процесса глубокой переработки птичьего помета

пользовать для производства топливных брикетов (рис. 1). Данная технология позволяет перерабатывать помет в потоке, сразу после его удаления из птичника. Тем самым снижается опасность загрязнения окружающей среды, исключаются затраты на организацию его хранения. В результате переработки помета появляется возможность производства востребованных и конкурентоспособных товаров, таких как горючий газ, тепловая энергия, органо-минеральное удобрение и при необходимости - топливные брикеты [6,7].

Результаты исследований. Математическое описание функционирования комплексного технологического процесса переработки помета можно представить функцией вида:

$$
\mathrm{y}_{\mathrm{i}}=\mathrm{f}_{\mathrm{i}}(\Sigma \mathrm{H}, \Sigma \mathrm{X}, \Sigma \mathrm{Z})
$$
совокупность контролируемых и регулируемых факторов; $\Sigma \mathrm{X}$ совокупность контролируемых где у - выходной параметр; $\Sigma \mathrm{H}$ - и не регулируемых факторов; $\Sigma Z$ - совокупность не контролируемых и не регулируемых факторов.

Так как не контролируемые факторы неизвестны, и установить их влияние на процесс переработки невозможно, то функцию (1) правильней выразить в виде:

$$
\mathrm{y}_{\mathrm{i}}=\mathrm{f}_{\mathrm{i}}(\Sigma \mathrm{H}, \Sigma \mathrm{X})
$$

Исходя из обобщенной схемы комплексного технологического процесса глубокой переработки помета, схема внешних связей может быть представлена как система с детализацией по основным технологическим модификациям помета (рис. 2). Эта схема представляет собой соединение отдельных технологических процессов, расположенных в технологической последовательности переработки помета. При этом отклики предыдущего процесса представляют собой входы последующего. Выход предыдущего технологического процесса может быть как управляемым, так и не управляемым входом последующего процесса.

В комплексном технологическом процессе существуют внешние связи, то есть связи между отдельными технологическими

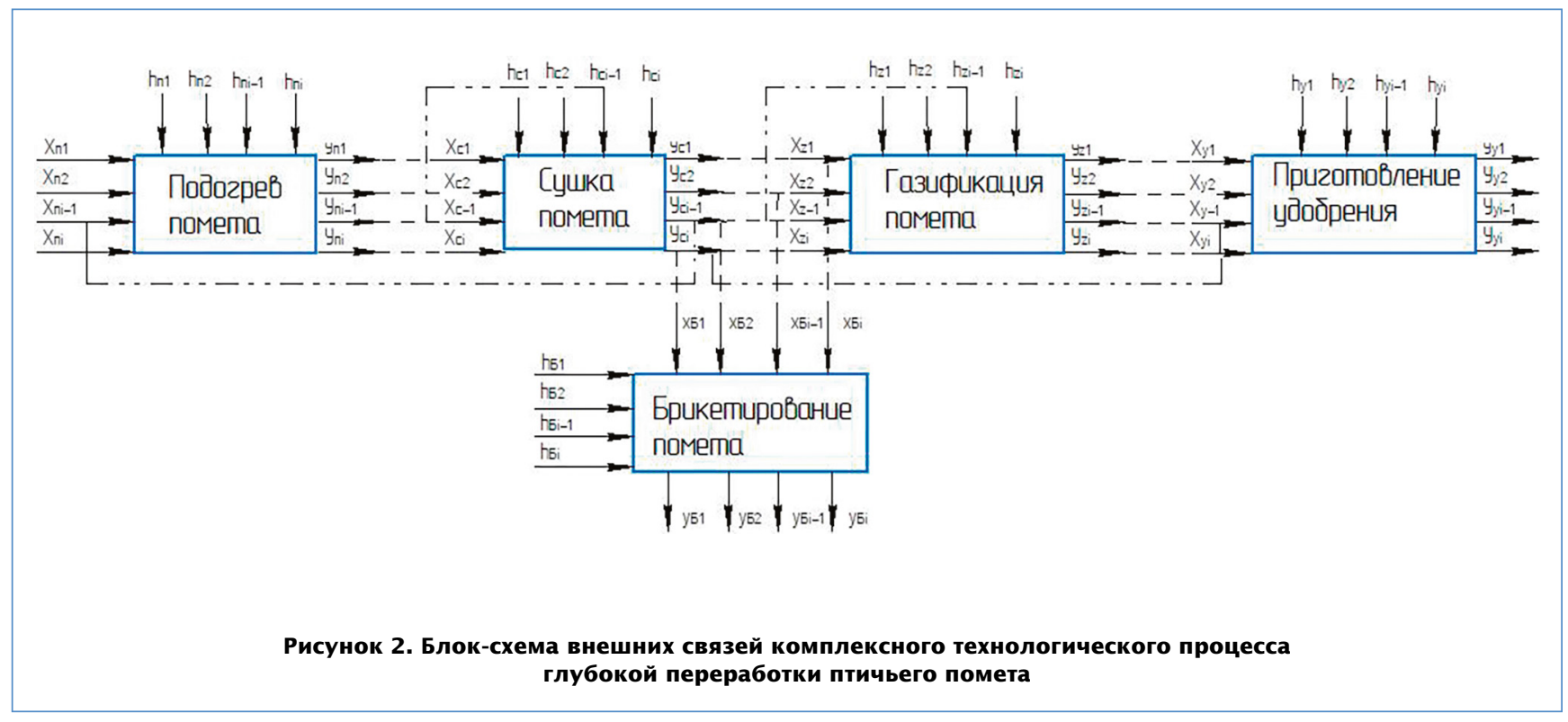




\begin{tabular}{|c|c|c|c|c|c|c|}
\hline \multirow{3}{*}{$\begin{array}{c}\text { Технологические } \\
\text { процессы }\end{array}$} & \multicolumn{6}{|c|}{ Факторы технологических процессов } \\
\hline & \multicolumn{4}{|c|}{ Входящие } & \multirow{2}{*}{ 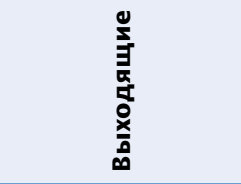 } & \multirow{2}{*}{$\begin{array}{l}y \\
y \\
\frac{y}{x} \\
\underline{x}\end{array}$} \\
\hline & $\begin{array}{c}\text { контролируемые } \\
\text { и регулируемые }\end{array}$ & 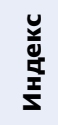 & $\begin{array}{l}\text { контролируемые } \\
\text { не регулируемые }\end{array}$ & $\begin{array}{l}y \\
y \\
\frac{y}{x} \\
\underline{x}\end{array}$ & & \\
\hline \multirow{5}{*}{$\begin{array}{c}\text { Подогрев } \\
\text { помета }\end{array}$} & масса помета & $\mathrm{X}_{\mathrm{nI}}$ & влажность помета & $\mathrm{h}_{\Pi 1}$ & масса помета & $\mathrm{y}_{\mathrm{n} 1}$ \\
\hline & $\begin{array}{c}\text { продолжительность } \\
\text { подогрева }\end{array}$ & $X_{\Pi 2}$ & температура помета & $\mathrm{h}_{\mathrm{n1}}$ & $\begin{array}{l}\text { температура } \\
\text { помета }\end{array}$ & $y_{\text {п2 }}$ \\
\hline & температура пара & $\mathrm{X}_{\text {пз }}$ & $\begin{array}{l}\text { температура воздуха } \\
\text { окружающей среды }\end{array}$ & $\mathrm{h}_{\Pi 1}$ & влажность помета & $\mathrm{y}_{\text {пз }}$ \\
\hline & температура помета & $\mathrm{X}_{\Pi 4}$ & $\begin{array}{c}\text { влажность воздуха } \\
\text { окружающей среды }\end{array}$ & $\mathrm{h}_{\Pi 1}$ & $\begin{array}{l}\text { количество } \\
\text { конденсата }\end{array}$ & $\mathrm{y}_{\text {п4 }}$ \\
\hline & расход теплоносителя & $\mathrm{X}_{\mathrm{75}}$ & & & & \\
\hline \multirow{4}{*}{$\begin{array}{c}\text { Высоко- } \\
\text { температурная } \\
\text { сушка помета }\end{array}$} & масса помета & $\mathrm{X}_{\mathrm{Cl}}$ & температура помета & $\mathrm{h}_{\mathrm{Cl}}$ & масса помета & $\mathrm{y}_{\mathrm{Cl}}$ \\
\hline & продолжительность сушки & $\mathrm{X}_{\mathrm{C} 2}$ & влажность помета & $\mathrm{h}_{\mathrm{C} 2}$ & влажность помета & $\mathrm{y}_{\mathrm{C2}}$ \\
\hline & температура нагрева помета & $\mathrm{X}_{\mathrm{C3}}$ & $\begin{array}{l}\text { температура воздуха } \\
\text { окружающей среды }\end{array}$ & $\mathrm{h}_{\mathrm{C3}}$ & $\begin{array}{c}\text { температура } \\
\text { помета }\end{array}$ & $y_{c 3}$ \\
\hline & расход газа на сушку & $\mathrm{X}_{\mathrm{C} 4}$ & $\begin{array}{l}\text { влажность воздуха } \\
\text { окружающей среды }\end{array}$ & $\mathrm{h}_{\mathrm{C} 4}$ & & $\mathrm{y}_{\mathrm{C4}}$ \\
\hline \multirow{6}{*}{ Газификация } & влажность помета & $X_{\Gamma 1}$ & $\begin{array}{l}\text { температура воздуха } \\
\text { окружающей среды }\end{array}$ & $\mathrm{h}_{\Gamma 1}$ & количество газа & $\mathrm{y}_{\Gamma 1}$ \\
\hline & масса помета & $X_{52}$ & $\begin{array}{l}\text { влажность воздуха } \\
\text { окружающей среды }\end{array}$ & $\mathrm{h}_{\ulcorner 2}$ & температура газа & $y_{12}$ \\
\hline & температура помета & $X_{\Gamma 3}$ & & & количество золы & $\mathrm{y}_{13}$ \\
\hline & температура нагрева & $X_{\Gamma 4}$ & & & температура золы & $\mathrm{Y}_{54}$ \\
\hline & $\begin{array}{c}\text { продолжительность } \\
\text { пиролиза }\end{array}$ & $X_{r 5}$ & & & $\begin{array}{c}\text { фракционный } \\
\text { состав золы }\end{array}$ & $\mathrm{y}_{55}$ \\
\hline & расход газа на пиролиз & $X_{\text {г6 }}$ & & & $\begin{array}{c}\text { количество } \\
\text { питательных } \\
\text { веществ в золе }\end{array}$ & $y_{\text {г6 }}$ \\
\hline \multirow{6}{*}{$\begin{array}{l}\text { Приготовление } \\
\text { органо-мине- } \\
\text { ральной смеси }\end{array}$} & количество золы & $x_{01}$ & $\begin{array}{c}\text { количество питательных } \\
\text { веществ в золе }\end{array}$ & $\mathrm{h}_{01}$ & количество смеси & $\mathrm{y}_{\mathrm{O}}$ \\
\hline & температура золы & $\mathrm{X}_{\mathrm{O} 2}$ & $\begin{array}{c}\text { количество питательных } \\
\text { веществ в помете }\end{array}$ & $\mathrm{h}_{\mathrm{O} 2}$ & влажность смеси & $\mathrm{y}_{\mathrm{O} 2}$ \\
\hline & фракционный состав золы & $\mathrm{X}_{\mathrm{O} 3}$ & влажность золы & $\mathrm{h}_{\mathrm{O} 3}$ & $\begin{array}{c}\text { количество } \\
\text { питательных } \\
\text { веществ }\end{array}$ & $\mathrm{y}_{\mathrm{O3}}$ \\
\hline & количество сухого помета & $\mathrm{X}_{\mathrm{O} 4}$ & влажность помета & $\mathrm{h}_{\mathrm{O} 4}$ & $\begin{array}{c}\text { качество } \\
\text { смешивания }\end{array}$ & $\mathrm{y}_{\mathrm{O} 4}$ \\
\hline & $\begin{array}{c}\text { количество } \\
\text { питательных веществ в } \\
\text { помете }\end{array}$ & $\mathrm{X}_{\mathrm{O5}}$ & & & затраты энергии & $\mathrm{y}_{\mathrm{OS}}$ \\
\hline & $\begin{array}{c}\text { продолжительность } \\
\text { смешивания }\end{array}$ & $\mathrm{X}_{\mathrm{O} 6}$ & & & & \\
\hline \multirow{4}{*}{ Брикетирование } & влажность помета & $X_{61}$ & диаметр брикета & $h_{61}$ & плотность брикета & $y_{51}$ \\
\hline & фракционный состав помета & $X_{62}$ & & & длина брикета & $\mathrm{y}_{52}$ \\
\hline & усилие сжатия & $X_{63}$ & & & $\begin{array}{l}\text { температура } \\
\text { брикета }\end{array}$ & $y_{53}$ \\
\hline & $\begin{array}{l}\text { температура } \\
\text { помета }\end{array}$ & $X_{54}$ & & & & \\
\hline
\end{tabular}

процессами, представленные в табл. 1.

Взаимодействие между операциями технологических процессов отражается внутренними связями. На этапе выполнения технологических операций процессов подогрева помета, высокотемпературной сушки, газифи- кации, приготовления органо-минерального удобрения $T_{i}^{j}$, происходит изменение состояния помета $C_{i}^{n}$. С учетом этого составим операторную схему комплексного технологического процесса глубокой переработки помета с внутренними связями технологических процессов (рис. 3).
Обозначим процессы подогрева помета, высокотемпературной сушки, газификации помета, приготовления органо-минерального удобрения передаточными коэффициентами $\Pi_{\Pi}, \Pi_{C}, \Pi_{\Gamma}, \Pi_{y}$ соответственно. Совокупность составляющих передаточных коэффициентов процесса глубокой перера- 


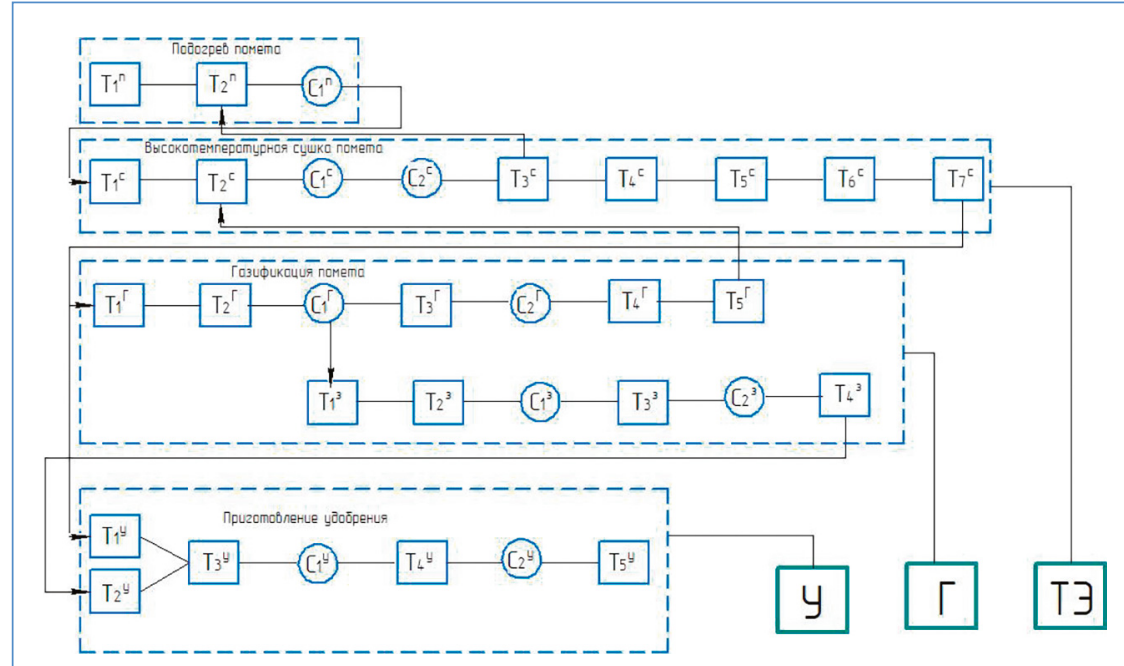

Рисунок 3. Операторная схема комплексного технологического процесса глубокой переработки помета: $T_{1}$ - подача помета в приемно-накопительную емкость; $\mathrm{T}_{2}{ }^{n}$ - подогрев помета паро-воздушной смесью; $\mathrm{C}_{1}{ }^{n}$ - повышение температуры помета; $\mathrm{T}_{1}{ }^{\mathrm{C}}$ - подача помета в сушилку; $\boldsymbol{n}_{2}{ }^{\mathrm{C}}$ - нагрев помета; С, C - повышение температуры помета; $\mathrm{C}_{2}{ }^{\mathrm{C}}$ - снижение влажности помета; $\mathbf{T}_{3}{ }^{\mathrm{C}}$ - удаление паро-воздушной смеси из сушилки; $\mathrm{T}_{4}{ }^{\mathrm{C}}$ - выгрузка высушенного помета из сушилки; $\mathrm{T}_{1}{ }^{\mathrm{r}}$ - подача высушенного помета в пиролизную установку; $T_{2}{ }^{r}$ - нагревание помета; $C_{1}{ }^{r}$ - газификация помета; $T_{3}{ }^{r}$ - охлаждение газа; $\mathrm{C}_{2}{ }^{\mathrm{r}}$ - снижение температуры газа; $\mathrm{T}_{4}{ }^{\mathrm{r}}$ - подача газа в газгольдер; $T_{5}{ }^{r}$ - подача газа на сушку помета; $T_{1}{ }^{3}$ - удаление золы из пиролизной установки; $\mathrm{T}_{2}{ }^{3}$ - охлаждение золы; $\mathrm{C}_{1}{ }^{3}$ - снижение температуры золы;

$\mathrm{T}_{3}{ }^{3}$ - измельчение золы; $\mathrm{C}_{2}{ }^{3}$ - образование порошкообразной структуры золы; $\mathrm{T}_{4}{ }^{3}$ - подача золы в накопительную емкость.

ботки помета представим в виде системы:

$$
\left\{\begin{array}{c}
\Pi_{\mathrm{n}}=\mathrm{T}_{1}^{\mathrm{n}} \mathrm{T}_{2}^{\mathrm{n}} \mathrm{C}_{1}^{\mathrm{C}} \\
\Pi_{\mathrm{c}}=\mathrm{T}_{1}^{\mathrm{c}} \mathrm{T}_{2}^{\mathrm{c}} \mathrm{C}_{1}^{\mathrm{c}} \mathrm{C}_{2}^{2} \mathrm{~T}_{3}^{\mathrm{c}} \mathrm{T}_{4}^{\mathrm{c}} \mathrm{T}_{5}^{\mathrm{c}} \mathrm{T}_{6}^{\mathrm{c}} \mathrm{T}_{7}^{\mathrm{c}} \\
\Pi_{\mathrm{r}}=\mathrm{T}_{1}^{\mathrm{r}} \mathrm{T}_{2}^{\mathrm{r}} \mathrm{C}_{1}^{\mathrm{r}} \mathrm{T}_{3}^{\mathrm{r}} \mathrm{C}_{2}^{\mathrm{T}} \mathrm{T}_{4}^{\mathrm{r}} \mathrm{T}_{5}^{\mathrm{r}}+\mathrm{T}_{1}^{3} \mathrm{~T}_{2}^{3} \mathrm{C}_{1}^{3} \mathrm{~T}_{3}^{3} \mathrm{C}_{2}^{3} \mathrm{~T}_{4}^{3} \\
\Pi_{y}=\mathrm{T}_{1}^{y} \mathrm{~T}_{2}^{y} \mathrm{~T}_{3}^{y} \mathrm{C}_{1}^{y} \mathrm{~T}_{4}^{y} \mathrm{C}_{2}^{y} \mathrm{~T}_{5}^{y}
\end{array}\right.
$$

При разработке очередного этапа переработки помета учитываем его состояние на предыдущем этапе, то есть решаем многоэтапную задачу, причем на каждом этапе предусматриваем выполнение определенного количества технологических операций для достижения желаемого результата. При этом отдельные операции не рассматриваются вследствие их достаточной изученности и неизменности.

\section{Выводы:}

1. Глубокая переработка птичьего помета является сложным технологическим процессом, направленным на экологически безопасную и экономически целесообразную утилизацию вещества, опасного для окружающей среды, с целью получения востребованных и конкурентоспособных продуктов - горючего газа, тепловой энергии и органо-минерального удобрения, а также, при необходимости, топливных брикетов.

2. Технологические процессы переработки помета осуществляются в определенной последовательности замкнутого цикла, при этом отклики предыдущего технологического процесса представляют собой как управляемые, так и не управляемые входы последующего процесса.

3. Для повышения эффективности процесса высокотемпературной сушки производится предварительный нагрев помета в приемно-накопитель- ной станции до температуры 30-35ㄷ паром, удаляемым из барабана сушилки, это обеспечивает снижение расхода энергии на сушку за счет рационального использования отработанной тепловой энергии, снижение затрат на конденсацию пара и сбор конденсата.

4. В процессе пиролиза высушенного помета образуется горючий газ, который используют для обеспечения самого процесса пиролиза, высокотемпературной сушки помета и на другие внутрихозяйственные нужды, например, на выработку электрической энергии.

5. При газификации помета остается зола, которая содержит питательные вещества, полезные для растений, и является основным компонентом при приготовлении органо-минерального удобрения.

\section{Литература}

1. Послание Президента Федеральному Собранию Российской Федерации, 20 февраля 2019 г. Источник: https:// www.egonline.ru/information/394150/. 2. ГОСТ 31461-2012 Помет птицы. Сырье для производства органических удобрений. Технические условия. М.: Стандартинформ, 2013. - 11 с.

3. Технологии и технические средства для переработки помета на птицефабриках / В.И. Фисинин, В.П. Лысенко [и др.]. - М.: НИПКЦ Восход-А, 2011. - 296 c.

4. Запевалов М.В. Утилизация птичьего помета // Вестник Челябинского агроинженерного университета. 2009. - Т. 54. - С. 124.

5. Запевалов М.В., Наумов Ю.М. Эффективность применения птичьего помета в качестве удобрения // Вестник Челябинского агроинженерного университета. - 2002. - Т. 37. - С. 118. 6. Запевалов М.В., Запевалов С.М. Переработка птичьего помета с получением электрической, тепловой энергии и 
комплексного органо-минерального удобрения // Вестник Челябинской государственной агроинженерной академии. - 2014. - Т. 67. - №1 . - С. 45-49. 7. Запевалов М.В., Качурин В.В., Бондаренко Н.В. Предпосылки глубокой переработки птичьего помета // Актуальные вопросы агроинженерных наук в сфере технического сервиса машин, оборудования и безопасности жизнедеятельности: теория и практика. Мат. нац. науч. конф. Института агроинженерии (Челябинск, 2020). Под ред. д-ра биол. наук, доцента С.А. Гриценко. - Челябинск: ЮжноУральский ГАУ, 2020. - С. 101-112.
Для контакта с авторами:

\section{Запевалов}

Михаил Вениаминович

Тел.: +7-951-489-96-97

Качурин Виталий Владимирович

Тел.: +7-919-342-40-78

Наруков Евгений Николаевич

тел.: +7-929-271-1111

\title{
Interrelations of the Technological Processes within the Technology of Deep Processing of Poultry Manure
}

\author{
Zapevalov M.V.' , Kachurin V.V.' ${ }^{1}$ Narukov E.N. ${ }^{2}$
}

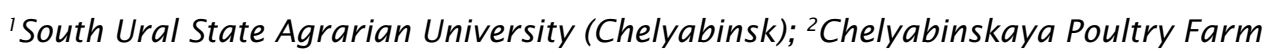

Summary: The technology of deep processing of poultry manure has been developed involving the processes of preliminary heating of the manure, high-temperature drying, briquetting, gasification by pyrolysis, production of an organomineral fertilizer. On the basis of this operational sequence the block-scheme of external interrelations between the detailed processes within the technology was developed. Each following process is designed on the basis of the condition of the manure after previous process; the entire technology is therefore designing as a multi-stage system with definite number of technological operations within each stage to obtain the desirable result. Individual stages are considered well developed and unalterable. The main influencing factors were determined and operational scheme of the technology was developed.

Keywords: poultry manure, processing, technological processes, interrelations, high-temperature drying, pyrolysis, organomineral fertilizer.

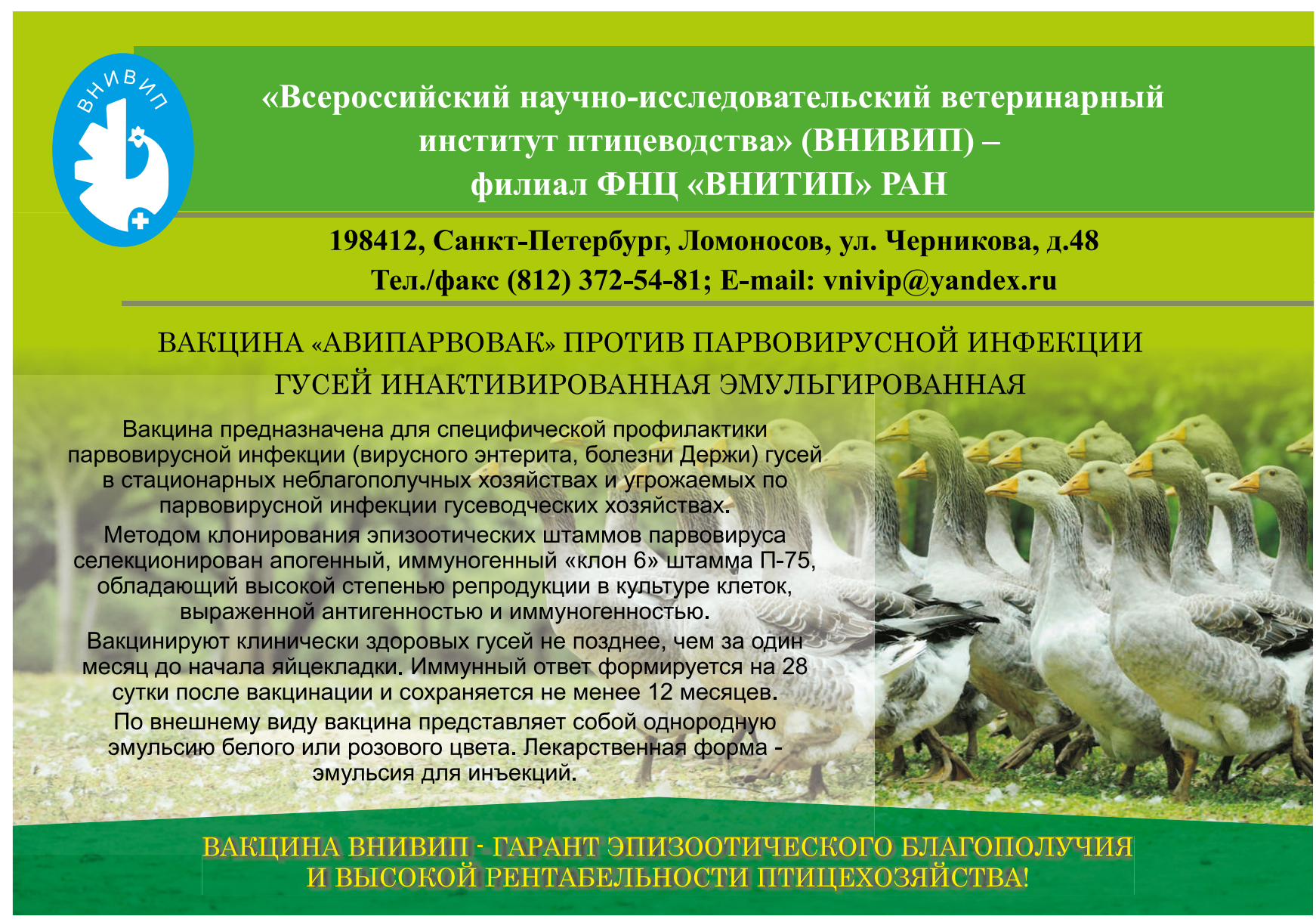

